\title{
Expression and Purification of HCV Core and Core-E1E2 Proteins in Different Bacterial Strains
}

\author{
Seyyedeh Masumeh Mirnurollahi 1, Azam Bolhassani 2,*, Shiva Irani 1, Noushin Davoudi 3 \\ ${ }^{1}$ Department of Biology, Science and Research Branch, Islamic Azad University, Tehran, Iran \\ ${ }^{2}$ Department of Hepatitis and AIDS, Pasteur Institute of Iran, Tehran, Iran \\ ${ }^{3}$ Biotechnology Research Center, Department of Medical Biotechnology, Pasteur Institute of Iran, Tehran, Iran \\ *Corresponding author: Azam Bolhassani, Department of Hepatitis and AIDs Pasteur Institute of Iran Tehran, Iran. Fax: +98-2166465132, Tel: +98- \\ 2166953311, E-mail: azam.bolhassani@yahoo.com, A_bolhasani@pasteur.ac.ir
}

Received: June 06, 2015; Revised: July 11, 2015; Accepted: August 17, 2015

Background: Hepatitis $\mathrm{C}$ virus (HCV) is a main public health problem causing chronic liver infection and subsequently liver cirrhosis and lethal hepatocellular carcinoma (HCC). Vaccination based on HCV capsid proteins has attracted a special interest for prevention of viral infections. The core protein is a basic and evolutionary most conserved protein, which regulates the cellular processes related to viral replication and pathogenesis. The envelope E1 and E2 proteins involve in generation of the infectious particles, viral entry by binding to a host cell receptor, and modulation of the immune responses.

Objectives: In current study, the efficient generation of recombinant core and core-E1E2 proteins was developed in bacterial expression systems.

Materials and Methods: The expression of HCV core and core-E1E2 proteins was performed using prokaryotic pET-28a and pQE-30 expression systems in BL21/ Rosetta, and M15 strains, respectively. The recombinant proteins were purified using affinity chromatography under native conditions and also reverse staining method. Finally, the levels of recombinant proteins were assessed by BCA kit and spectrophotometer.

Results: The data showed a clear band of $\sim 573 \mathrm{bp}$ for HCV core and $\sim 2238$ bp for core-E1E2 genes in agarose gel. Moreover, a $\sim 21 \mathrm{kDa}$ band of core protein and a $\sim 83 \mathrm{kDa}$ band of core-E1E2 protein were revealed in SDS-PAGE. The affinity chromatography could not purify the core and core-E1E2 proteins completely, because of low affinity to Ni-NTA bead in comparison with reverse staining method.

Conclusions: This study is the first report for purification of HCV core and core-E1E2 proteins using the reverse staining procedure with no need of any chromatography columns. The BL21 strain was more potent than Rosetta strain for HCV core protein in pET 28a expression system. Furthermore, M15 strain was suitable for expression of coreE1E2 in pQE-30 bacterial system.

Keywords: Bacterial expression systems; Core nucleocapsid; E1E2 glycoprotein; HCV; Protein purification; Reverse staining

\section{Background}

Regarding the WHO report, Hepatitis C virus (HCV) infections affect about 170 million people $(\sim 3 \%)$ in the world $(1,2)$. HCV belongs to the Flaviviridae family and has positive single strand RNA in genome with length of $9.6 \mathrm{~Kb}(3,4)$. The $\mathrm{HCV}$ polyprotein is divided into three structural proteins including the nucleocapsid or core protein and the two envelope glycoproteins, E1 and E2, and seven nonstructural proteins (NS2, NS3, NS4A, NS4B, NS5A, NS5B) $(3,4)$. The core protein plays an important role in the formation of the capsid shell, and influences various host cell functions such as gene transcription, lipid metabolism, cell signaling, and apoptosis $(1,5$, $6)$. The envelope glycoproteins usually contain $\mathrm{N}$ linked glycans that may participate in folding, fusion with the membrane of the host cell (entry functions), and modulating the immune responses (7). The humoral immune response to HCV infection is polyclonal antibody directed against viral antigens. Antibodies directed against the envelope proteins of the HCV virus are considered the first candidates for virus-neutralizing antibodies $(8,9)$. However, there is no effective HCV vaccine due to very low levels of viral particles in plasma or liver tissues of infected patient, and the lack of convenient tissue culture sys- 
tems and also animal models $(5,10,11)$. Therefore, the use of recombinant proteins especially structural proteins can be considered as an important strategy in stimulation of humoral immune responses. Many studies have produced HCV core or HCV core-E1E2 proteins in different expression systems such as bacteria $(12,13)$, insects $(4,10,14)$, and yeast $(15,16)$. Usually, the truncated fragments of core, E1 or E2 were produced in bacterial systems (17). In this study, we developed the production of the full length $\mathrm{HCV}$ core and also core-E1E2 protein using bacterial expression system and reverse staining method for the first time. Indeed, the zinc/imidazole reverse staining procedure based on differential salt binding was used for visualizing and separating proteins in acrylamide gel.

\section{Objective}

In current study, the recombinant proteins of $\mathrm{HCV}$ core and core-E1E2 linked to a His-tag were generated using different prokaryotic expression systems. For the first time, we used the reverse staining procedure for purification of the recombinant proteins.

\section{Materials and Methods}

\subsection{Cloning of Core and Core-E1E2 in pET-28a and pQE-30 Plasmids}

The sequences of HCV core and core-E1E2 genes were obtained from GenBank (Accession number: $\mathrm{AB}$ 047640). The design of primers and the restriction enzymes were performed to clone the full length of core ( $\sim 573 \mathrm{bp})$ and core-E1E2 ( 2238 bp) in pET-28a and $\mathrm{pQE}-30$ vectors, respectively (Table 1 ).

PCR reaction was carried out within 35 cycles for core gene (denaturation at $94^{\circ} \mathrm{C}$ for $1 \mathrm{~min}$, annealing at $55^{\circ} \mathrm{C}$ for $1 \mathrm{~min}$, and elongation at $72^{\circ} \mathrm{C}$ for $1 \mathrm{~min}$ ). The same PCR reaction was performed for core-E1E2 with different annealing temperature $\left(58^{\circ} \mathrm{C}\right)$ and elongation time for $2 \mathrm{~min}$ using PFU DNA polymerase (Fermentase, Germany). The PCR product was separated in electrophoresis using $1 \%(\mathrm{w} / \mathrm{v})$ agarose gel, stained by ethidium bromide, and visualized under a
UV transilluminator. The restriction enzymes were BamHI/SacI (Fermentas) for core cloning into pET28a plasmid and BamHI/HindIII (Fermentas) for coreE1E2 cloning into pQE-30 plasmid. After gel extraction (Qiagen kit), the ligation of core gene into $\mathrm{pET}$ and also core-E1E2 gene into $\mathrm{pQE} 30$ was done by T4 DNA ligase (Fermentas) overnight at $14^{\circ} \mathrm{C}$. Next, $E$. coli $\mathrm{DH} 5 \alpha$ strain was transformed by the ligation solutions consisting $\mathrm{pET}$-core or $\mathrm{pQE}$-core-E1E2. A single colony of each transformant was grown in LB media containing ampicillin (100 $\left.\mu \mathrm{g} . \mathrm{mL}^{-1}\right)$ for pQEcoreE1E2 and kanamycin $\left(25 \mu \mathrm{g} . \mathrm{mL}^{-1}\right)$ for pET-core at $37^{\circ} \mathrm{C}$ for $12-14 \mathrm{~h}$. Plasmids were purified using mini-kit (Qiagen) verified by PCR or digestion, and sequenced using the dideoxy chain termination method on an automated sequencer. Finally, the recombinant plasmids were transformed into $E$. coli BL21 (DE3) and also Rosetta strains for core and M15 for core-E1E2. A single colony of transformant was grown in LB media containing kanamycin for BL21 and Rosetta, and kanamycin and ampicillin for M15 strain at $37^{\circ} \mathrm{C}$ for $12-14 \mathrm{~h}$.

\subsection{Expression of Core and Core E1E2 Proteins in E. coli BL21, Rosetta, and M15 Strains}

The positive bacterial clones were inoculated in 50 $\mathrm{ml}$ TY2X medium and grown to an optical density of 0.7-0.8 at $600 \mathrm{~nm}$. The expression of core and coreE1E2 genes was induced by adding $1 \mathrm{mM}$ IPTG and the pellet was harvested at $3 \mathrm{~h}$ post-induction. The pellet was dissolved in $50 \mu \mathrm{L}$ of SDS sample buffer $2 \mathrm{X}$ and boiled for $5 \mathrm{~min}$. Total proteins were analyzed by SDS-PAGE in $12.5 \%(\mathrm{~W} / \mathrm{V})$ polyacrylamide gel (SDS gel apparatus; BioRad), followed by staining with coomassie brilliant blue.

\subsection{Protein Purification}

3.3.1. Protein Purification by Affinity Chromatography using Ni-NTA Column

The HCV core and also core-E1E2 proteins were purified under native conditions on a nickel-nitrilotriacetic acid (Ni-NTA)-agarose column according to the

Table 1. Polymerase Chain Reaction

\begin{tabular}{|c|c|c|c|c|}
\hline Primers & Forward(5'-3') & Reverse $\left(5^{\prime}-3^{\prime}\right)$ & $\mathrm{Tm}$ & Product size \\
\hline Core & $\begin{array}{c}\text { CCGGGATCCATGGGCACAAATCCTAAACCTCAAAG } \\
(\text { (BamHI) }\end{array}$ & $\begin{array}{l}\text { TGGAGCTCCTTAAGAGCAGAGACCG- } \\
\text { GAACGGTG(Sacl, AfllI) }\end{array}$ & $55^{\circ} \mathrm{C}$ & $573 b p$ \\
\hline Core-E1-E2 & $\begin{array}{l}\text { CCGGGATCCATGGGCACAAATCCTAAACCTCAAAG } \\
\text { (BamHI) }\end{array}$ & $\begin{array}{l}\text { ATAAGCTTTGCTTCGGCCTGGCC- } \\
\text { CAACAAG(Hind III) }\end{array}$ & $58^{\circ} \mathrm{C}$ & $2238 b p$ \\
\hline
\end{tabular}


manufacturer protocol (Qiagen). Briefly, the cell pellet was solved in lysis buffer A (10 mM Immidazol, $\mathrm{pH} 8$ ) and placed in ice for $30 \mathrm{~min}$ and then sonicated for 20 min. The supernatant was recovered after centrifuging the disrupted cell suspension in $4000 \times \mathrm{g}$ for $20 \mathrm{~min}$ at $4^{\circ} \mathrm{C}$. The lysate was applied on the Ni-NTA column (Qiagen). Following three washes by buffer B $(30 \mathrm{mM}$ Immidazol, and $\mathrm{pH} 8$ ), purified protein was eluted by $300 \mathrm{mM}$ imidazole elution buffer ( $\mathrm{pH}$ 8). Purified core and core-E1E2 proteins were analyzed by $12 \%$ SDSPAGE.

\subsubsection{Protein Purification by Reverse Staining Method}

The bacterial pellets containing core and also coreE1E2 were dissolved in lysis buffer and placed on ice for $30 \mathrm{~min}$. The lysates were sonicated for $20 \mathrm{~min}$ and the samples were dissolved in sample buffer $6 \times$ and boiled for $5 \mathrm{~min}$. The core and core-E1E2 proteins were analyzed by SDS-PAGE. An imidazole-SDS-Zn reverse staining method was used for the purifications as described earlier (18). The purified proteins were concentrated and dialyzed against PBS (dialysis membrane, MWCO: $3.500 \mathrm{kDa}$ ). Protein concentration was measured using BCA assay kit (Pierce, USA) and spectrophotometer. The recombinant protein was kept at $-20^{\circ} \mathrm{C}$ until use.

\section{Results}

\subsection{Construction and Expression of the Recombinant Core and Core-E1E2 Proteins in E. coli}

The recombinant plasmids expressing $\mathrm{HCV}$ core and core-E1E2 proteins were confirmed by digestion as well as PCR analysis indicating core and core-E1E2 gene amplification. The results showed a clear band of $\sim 573$ bp for HCV core and 2238 bp for core-E1E2 gene in agarose gel (Figure 1). In addition, a $\sim 21 \mathrm{kDa}$ band for core protein and $\sim 83 \mathrm{kDa}$ for core-E1E2 protein were revealed in bacterial system using SDSPAGE (Figures 2). The pET expression system was efficient for expression of $\mathrm{HCV}$ core protein, while the pQE expression system was convenient for expression of HCV core-E1E2 protein. Furthermore, the type of bacterial strain was an important factor for high core protein expression. Indeed, the level of core protein expression in BL21 (DE3) was higher than that in Rosetta strain (Data not shown).

\subsection{Purification of Core and Core-E1E2 from E. coli}

The purification of core and core-E1E2 was performed by two different methods such as affinity chromatography with Ni-NTA column, and reverse staining procedure. The results showed that the reverse staining method based on Zn-Imidazole-SDS was more efficient than affinity chromatography for protein purification (Figure 2). The Ni-NTA could not purify completely the core and core-E1E2 proteins as compared to reverse staining method. Total protein concentration of the samples, was assessed using BCA kit and spectrophotometer for next tests. The amounts of proteins were variable with changing culture volume. Generally, the amounts were obtained as 300-400 $\mu \mathrm{g} . \mathrm{mL}^{-1}$ and 100-200 $\mu \mathrm{g} . \mathrm{mL}^{-1}$ for core and coreE1E2 proteins, respectively.

\section{Discussion}

The studies showed that HCV core antigen is a major target to improve $\mathrm{HCV}$ preventive vaccines.



Figure 1. A: The confirmation of core and core-E1E2 genes by PCR and B: digestion on 1\% agarose gel; Molecular weight marker (1 Kb, Fermentas) is indicated as MW 

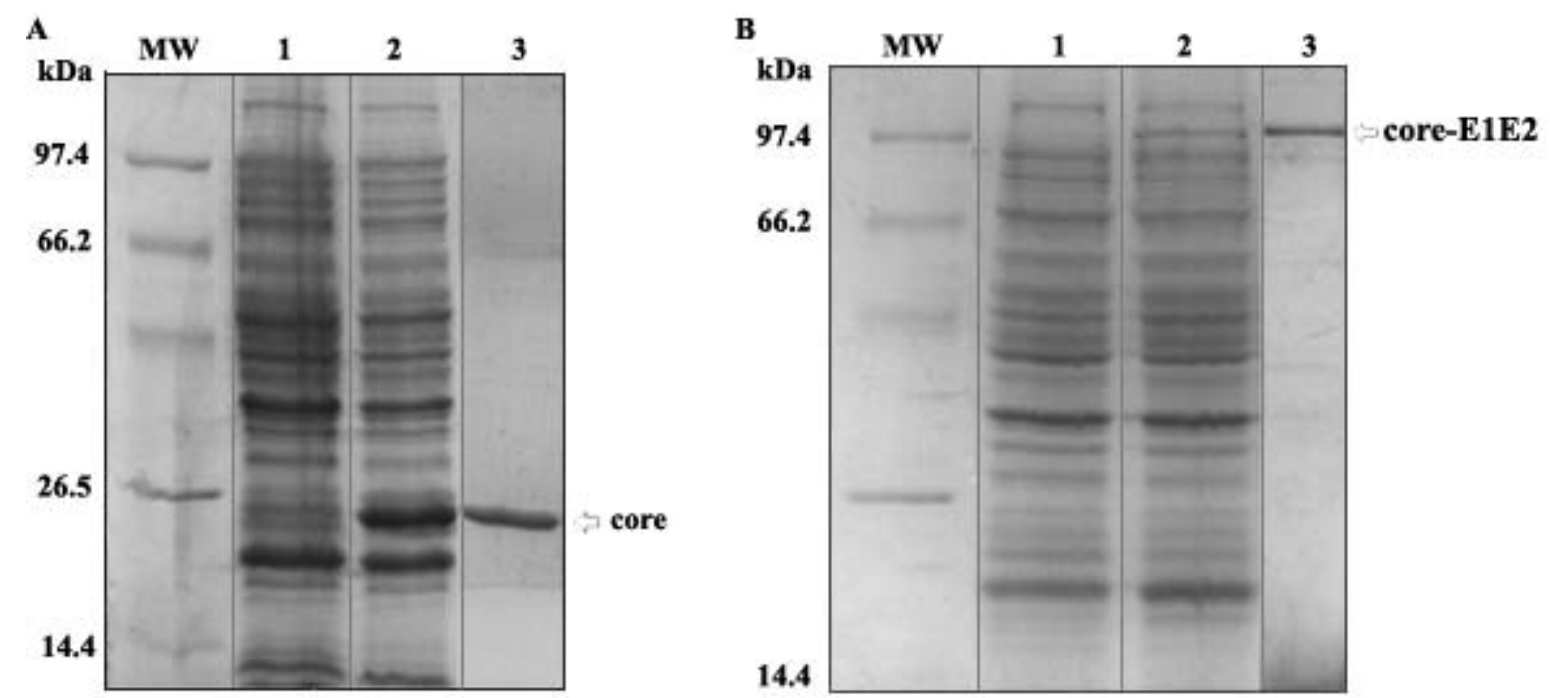

Figure 2. A: Expression and purification of core and B: core-E1E2 proteins in E. coli system: SDS-PAGE electrophoresis of lysate of uninduced (Lane 1) and IPTG (1 mM) induced (Lane 2) culture of E. coli and the recombinant protein purified by reverse-staining method (Lane 3). The weight of the molecular mass markers (Premixed protein molecular weight marker: $14.4-97.4 \mathrm{kDa}$ ) is indicated as MW

One of the major problems in development of $\mathrm{HCV}$ vaccine is its wide genetic variants. It has been shown that core antigen is a highly conserved protein (2). Serum antibodies against HCV core protein epitopes (residues 7-21, 31-45, 49-63, 99-113) were shown in $\mathrm{HCV}$ patients. Due to contribution of all amino acid residues of $\mathrm{HCV}$ core, total of 191 amino acids of this protein were included in vaccine design. Indeed, the conservative feature of the core gene in different $\mathrm{HCV}$ genotypes and the low susceptible of mutation in this region, make this protein an ideal candidate for $\mathrm{HCV}$ vaccine (2). Therefore, the production of core protein was done in different expression systems (12-17). The use of bacterial systems showed promising results as compared to other eukaryotic systems such as insect cells and yeast because of less time for production, high-level yield, and cost-effectiveness ((3)). For example, the expression of core in E. coli BL21 using pGEX4T-2 (3) or pGEMEX-1 (1) expression vectors was performed using IPTG inducer as a recombinant fusion protein (e.g., GST fused protein). In these studies, HCV core was purified through affinity chromatography (3). The authors showed that during viral morphogenesis, HCV core protein is cleaved by cellular signal peptidase into the truncated core proteins of 191 and 173 with molecular weights of 21 and $19 \mathrm{kDa}$, respectively $(19,20)$. Three major domains could be determined in the $21 \mathrm{kDa}$ core fragment $(21,22)$. The hydrophilic domain containing an immunodominant epitope is among the first 121 amino acids of core sequence which can induce antiviral immune responses (23). Therefore, some studies generated the truncated fragments of $\mathrm{HCV}$ core, e.g., expression of the hydrophilic domain of core antigen (2-122 aa) in $E$. coli BL21 using an arabinose induction system. This fragment was purified in native condition on a NiNTA-agarose column (17). In other study, pQE-60 and pQE-30 plasmids were used for expression of the fragments of HCV structural and nonstructural proteins in E. coli. The fragments containing core (1-98 aa), NS3 (202-482 aa), and tetramer of hypervariable region 1 (HVR1) of E2 protein could be expressed in high levels in JM109 E. coli and purified by affinity chromatography for mice immunization (24). Furthermore, production of $\mathrm{HCV}$-like particles in insect cells were performed using a recombinant Baculovirus containing the cDNA of the HCV core-E1E2 structural proteins $(4,10)$.

Up to now, the expression of core-E1E2 was not reported in bacterial systems. In addition, the full length of HCV core was expressed using fusion bacterial vectors (e.g., GST tag) that needs further isolation and purification processes. Also, Ni-NTA was used as a common method for purification by His-tag.

In current study, we used two different expression vectors including $\mathrm{pET}-28 \mathrm{a}$ for core expression in Rosetta and DE3 strains, and pQE-30 for core-E1E2 expression in M15 strain. SDS-PAGE analyses of IPTG-induced cell lysates showed the presence of a prominent protein band that was not detectable in non- 
induced cell lysates. In the presence of SDS and 2mercaptoethanol, the core and core-E1E2 protein migrated as a $21 \mathrm{kDa}$ and $83 \mathrm{kDa}$ protein during electrophoresis, respectively. The results showed that the core protein expression in BL21 (DE3) was higher than that in Rosetta. In addition, the $\mathrm{pET}$ and $\mathrm{pQE}$ expression systems were efficient for generation of $\mathrm{HCV}$ core and core-E1E2 proteins, respectively, among other bacterial expression systems. On the other hand, the purification of recombinant core and coreE1E2 could be performed using affinity chromatography and reverse staining method. However, Ni-NTA could not purify completely the recombinant proteins as compared to reverse staining method.

Briefly, a variety of expression systems are available for protein production. Among them, E. coli has significant advantages of cost, ease of use and scale, which make it suitable to generate heterologous proteins. Improving the generation of recombinant proteins in $E$. coli generally involves changing several factors such as temperature, the expression strain, promoters, and induction conditions (25). In addition, there are a number of common fusion tags (e.g. His-tag) that are used to increase the efficiency of protein purification in $E$. coli. Herein, we showed a rapid protein elution from polyacrylamide gel bands at room temperature by reverse staining for preparation of core and coreE1E2 proteins $(26,27)$. Zinc-mediated protein fixation in the gel is fully reversible and the eluted biomolecules are neither chemically modified nor contaminated with organic dyes. This method can detect the bands corresponding to $5 \mathrm{ng}$ of protein (28). In conclusion, two factors are important for efficient generation of proteins: strains and purification method. This study indicated the production of core and core-E1E2 proteins in two E. coli systems purified by reverse staining with Imidazole/Zinc. Future studies will be considered to use the recombinant core and core-E1E2 proteins for anti-viral vaccine design.

\section{Acknowledgements}

We would like to acknowledge Elnaz Agi and Fatemeh Motevalli (Pasteur Institute of Iran) for technical assistance. This project was supported by Pasteur Institute of Iran (ID: 689).

\section{Authors' contribution}

MM performed experiments, analyzed data and wrote manuscript. AB supervised the study, analyzed data, and corrected the manuscript. SI and ND provided consultation.

\section{References}

1. Kazemi B, Bandehpour M, Seyed N, Roozbehi M, Mosaffa N. Cloning and expression of hepatitis $\mathrm{C}$ virus core protein in pGemex-1 expression vector. Arch Iran Med. 2008;11(2):173178. DOI: 08112/AIM.0010

2. Torbati E, Bandehpour M, Pakzad P, Mosaffa N, Koochaki A, Kazemi B. The evaluation of hepatitis $\mathrm{C}$ virus core antigen in immunized BALB/c mice. Hepat Mon. 2012;12(6):391-397. DOI: $10.5812 /$ hepatmon.6141

3. Yousaf MZ, Idrees M, Saleem Z, Rehman IU, Ali M. Expre ssion of core antigen of HCV genotype $3 \mathrm{a}$ and its evaluation as screening agent for HCV infection in Pakistan. Virol J. 2011;8:364. DOI: 10.1186/1743-422X-8-364

4. Baumert TF, Ito S, Wong DT, Liang TJ. Hepatitis C virus structural proteins assemble into viruslike particles in insect cells. J Virol. 1998;72(5):3827-3836.

5. Polyak SJ, Klein KC, Shoji I, Miyamura T, Lingappa JR. Assemble and Interact: Pleiotropic Functions of the HCV Core Protein. In: Hepatitis C Viruses: Genomes Molecular Biology. Tan SL, editor. Norfolk (UK). 2006.

6. Boulant S, Vanbelle C, Ebel C, Penin F, Lavergne JP. Hepatitis $\mathrm{C}$ virus core protein is a dimeric alpha-helical protein exhibiting membrane protein features. J Virol. 2005;79(17):1135311365. DOI: $10.1128 /$ JVI.79.17

7. Goffard A, Callens N, Bartosch B, Wychowski C, Cosset FL, Montpellier C, Dubuisson J. Role of N-linked glycans in the functions of hepatitis $\mathrm{C}$ virus envelope glycoproteins. J Virol. 2005;79(13):8400-8409. DOI: 10.1128/JVI

8. Grammatikos AP GE. Recent trends in the immune response against hepatitis C virus. Ann Gastroenterol. 2005;18:46-55.

9. Tarr AW, Urbanowicz RA, Ball JK. The role of humoral innate immunity in hepatitis C virus infection. Viruses. 2012;4(1):127. DOI: $10.3390 / \mathrm{v} 4010001$

10. Yazdani-Neyshabouri SH AM, Jahanian Najafabadi A, Bouzari S, Arashkia A, Sadat SM, Siadat SD, Sadigh ZA, Hekmat S, Pouriayevali MH and Kashanizadeh N. Expression of recombinant hepatitis $\mathrm{C}$ virus (HCV) Core, E1 and E2 proteins by the baculovirus expression vector system. Afr J Microbiol. 2012;6:4152-4157. DOI: 10.5897/AJMR11 1494.

11. Murata K, Lechmann M, Qiao M, Gunji T, Alter HJ, Liang TJ. Immunization with hepatitis $\mathrm{C}$ virus-like particles protects mice from recombinant hepatitis $\mathrm{C}$ virus-vaccinia infection. Proceedings of the National Academy of Sciences of the United States of America. 2003;100(11):6753-8. DOI: 10.1073pnas. 1131929100

12. Hemmat JYB, Khajeh KH, Moosavi-Movahedi AA, Karkhane AA. Over-expression of full-length core protein of hepatitis $\mathrm{C}$ virus by Escherichia coli cultivated in stirred tank fermentor. Iran J Biotechnol. 2011;9:245-252.

13. Linbai Ye JG, Xiaolin M, Jinping Xu, Ying Z, Min H, Lei M. Expression of E1 gene of a hepatitis C virus in E. coli and protein purification. J Nat Sci. 1996;1:279-282. DOI: 10.1007/ BF02901243

14. Choi SH, Kim SY, Park KJ, Kim YJ, Hwang SB. Hepatitis C virus core protein is efficiently released into the culture medium in insect cells. J Biochem Molecul Biol. 2004;37(6):73540. DOI: 10.5483/BMBRep 
15. Fazlalipour MKH, Monavari SHR, Mollaie HR. Recombinant core-e1e2 protein expressed in Pichia pastoris yeast, a candidate vaccine for hepatitis C virus. $J$ Antivir Antiretrovir. 2014;6:139-147. DOI: 10.4172/jaa.10000110

16. Donato GMRN, Grillo JM, Musacchio A, Vina A, Alvarez C, Figueroa N, Guerra I, Garcia J, Varas L, Muzio V, DuenasCarrera S. Expression and processing of hepatitis C virus structural proteins in Pichia pastoris yeast. Biochem Biophys. 2006;342:625-631. DOI: 10.1016/j.bbrc.2006. 01.157

17. Aghasadeghi MR SS, Budkowska A, Khabiri AR, Amini S, Bahramali G, Naddaf SR, Roohvand F. Evaluation of a native preparation of HCV core protein (2-122) for potential applications in immunization, diagnosis and $\mathrm{mAb}$ production. Iranian J Publ Health. 2006;35:1-10.

18. Simpson RJ. Zinc/Imidazole procedure for visualization of proteins in gels by negative staining. $\mathrm{CSH}$ protocols. 2007;pdb prot4701

19. McLauchlan J, Lemberg MK, Hope G, Martoglio B. Intramembrane proteolysis promotes trafficking of hepatitis $\mathrm{C}$ virus core protein to lipid droplets. EMBO J. 2002;21(15):3980-3988. DOI:10.1093/emboj/cdf414

20. McLauchlan J. Properties of the hepatitis $C$ virus core protein: a structural protein that modulates cellular processes. $J$ viral hepatitis. 2000;7(1):2-14. DOI: 10.1046/j.1365-2893.2000. 00201.x

21. Hitomi Y, McDonnell WM, Baker JR, Askari FK. High efficiency prokaryotic expression and purification of a portion of the hepatitis $\mathrm{C}$ core protein and analysis of the immune response to recombinant protein in $\mathrm{BALB} / \mathrm{c}$ mice. Viral Immunol. 1995;8(2):109-19. DOI: 10.1089/vim.1995.8. 109
22. Majeau N, Gagne V, Boivin A, Bolduc M, Majeau JA, Ouellet $\mathrm{D}$, et al. The N-terminal half of the core protein of hepatitis $\mathrm{C}$ virus is sufficient for nucleocapsid formation. J Gener Virol. 2004;85(Pt 4):971-81. DOI: 10.1099/vir.0. 79775-0

23. Alvarez-Obregon JC, Duenas-Carrera S, Valenzuela C, Grillo JM. A truncated HCV core protein elicits a potent immune response with a strong participation of cellular immunity components in mice. Vaccine 2001;19(28-29):3940-3946. DOI: $10.1016 / \mathrm{s} 0264-410 \mathrm{X}$ (01)00141-144

24. Mihailova M, Fiedler M, Boos M, Petrovskis I, Sominskaya I, Roggendorf M, et al. Preparation of hepatitis $\mathrm{C}$ virus structural and non-structural protein fragments and studies of their immunogenicity. Protein Expres Purif. 2006;50(1):43-48. DOI: 10.1016/j.pep.2006.06.011

25. Esposito D, Chatterjee DK. Enhancement of soluble protein expression through the use of fusion tags. Curr Opin Biotech. 2006;17(4):353-358. DOI:10.1016/j.copbio.2006 .6.003.

26. Chen HM. Revisit of imidazole-zinc reverse stain for protein polyacrylamide gel electrophoresis. Meth Mol Biol. 2012;869:487-495. DOI: 10.1007/978-1-61779-821-4_43.

27. Fernandez-Patron C, Castellanos-Serra L, Rodriguez P. Reverse staining of sodium dodecyl sulfate polyacrylamide gels by imidazole-zinc salts: sensitive detection of unmodified proteins. Bio Techniques. 1992;12(4):564-573.

28. Ferreras MGJ, Garcia-Segura JM. A permanent $\mathrm{Zn}^{+2}$ reverse staining method for the detection and quantification of proteins in polyacrylamide gels. Anal Biochem. 1993;213:206212. DOI: $10.1006 /$ abio. 1993.1410 